\title{
취약국가의 이해: \\ INCAF와 국제협력 기구의 논의를 중심으로
}

권혁주1) 서울대학교 행정대학원 교수

\section{목차}

I. 들어가며

II. 취약국가 개념의 정책적 배경

III. 취약국가의 개념과 이론적 검토

IV. 분쟁 및 취약성에 관한 국제네트워크:

OECD/DAC의 INCAF

$\vee$.한국의 취약국가 협력 정책에 대한 시사점

\section{I. 들어가며}

2010년부터 한국은 OECD/DAC에 정식회원으로서 활동하면서 국제사회에 새로운 공여국 (Emerging Donor)으로서 위상을 높여가고 있다. 이에 따라 국제개발협력의 중요한 정책과제에 대한 한국의 입장과 정책방안을 구축하고, 이를 기초로 국제사회와 협력을 이루어야 할 것이다. 이러한 맥락에 서 $\mathrm{OECD} / \mathrm{DAC}$ 가 국제개발협력에서 가장 어려운 과제 가운데 하나로 설정하고 있는 분쟁 및 취약 국가에 대한 지원방안에 대해서도 심도있는 정책적 대안을 마련하는 것이 시급한 과제로 제기되고 있다. 더욱이 2011년 한국에서 개최될 원조의 효과성을 위한 고위급 회담(Hign Level Forum)에 서 취약국가에 대한 개발협력 정책의 효과성 검토가 이루어진다는 점을 감안할 때 이러한 정책대 안 마련의 필요성이 절실히 요구된다. 이러한 맥락에서 국제개발협력 분야에서 진행되고 있는 취

1) 본 연구는 국제개발협력학회에서 수행하는 '한국 ODA의 분쟁 및 취약국가 지원방안 연구'를 기초로 하고 있음. 연구진 은 필자와 더불어 이환성, 배재현, 노우영, 동그라미, 이유주로 구성됨 
약국가에 대한 정책적 접근 등을 살펴보고, 여기에서 논의되는 취약국가의 개념정의, 개발협력 전 략 등을 비판적으로 분석해 본다. 나아가 한국의 $\mathrm{ODA}$ 의 정책에 주는 시사점이 무엇인지를 살펴보 기로 한다.

\section{II. 취약국가 개념의 정책적 배경}

최근 취약국가의 개념이 국제개발협력 논의에서 중요한 의미를 갖게 된 데에는 다양한 배경들이 존재한다. 이러한 다양한 흐름들을 정리하면 대체적으로 세 가지로 요약될 수 있는데, 이 절에서 는 이에 대해 간략히 살펴보기로 한다.

\section{MDG와 취약국가}

저개발과 빈곤 문제를 해결하기 위한 국제사회의 다양한 노력에도 불구하고 이는 여전히 해결해야 할 과제로 대두되고 있다. 세계 인구의 $1 / 6$ 인 10 억 명이 빈곤에 시달리고 있으며, 이들 가운데 3 분의 1 은 하루 1 달러 미만의 수입으로 생활하고 있다. 지속적인 국제사회의 노력에도 불구하고 빈 곤감소가 효과적으로 나타나지 않는 원인으로 취약국가가 제시되고 있다. 빈곤인구의 대부분이 취 약국가라고 분류될 수 있는 나라에 살고 있기 때문이다. 전세계 5세 이하 영아 사망률의 절반이 취약국가에서 발생하며, 임신이나 출산으로 인한 여성 사망률의 $1 / 3$ 이 취약국가에서 집계된다.

이러한 지표들은 2015년까지 MDGs 달성이 쉽지 않음을 보여주고 있다. 이에 OECD/DAC을 비롯 한 국제개발협력 기구들은 효과적인 MDGs의 달성을 위해 취약국가의 이해와 체계적인 접근의 필 요성을 공유하고 있으며, 취약국가라는 개념을 통해 개발도상국 혹은 저개발국가의 발전 문제에 접근하고 있다.

이러한 접근은 1980년 말부터 1990년대 초반까지 Washington Consensus를 기반으로 한 시장경 제 발전 패러다임과 이에 대한 반성으로 제기된 Good Governance에 기초한 논의와는 상당한 차 이를 보이고 있다는 점에서 주목할 만하다. 취약국가의 시각에서 보면 많은 개발도상국 혹은 저개 발국가 가운데 취약성이 높은 나라들은 시장경제가 원활히 작동할 수 있는 제도적 기반이 마련되 어 있지 않는 경우가 대부분이다. 따라서 이들 국가에서 시장경제에 기반한 전략은 적실정이 높지 않다. 한편 Good Governance가 경제, 사회적 발전을 창출한다는 주장도 취약국가에서는 적절한 대안이 되지 못한다. 정책 투명성, 정책 책임성, 신뢰와 소통의 제도적 기반이 갖추어 있지 못한 
국가에서 Good Governance가 전제하고 있는 발전의 논리가 성립할 수 없기 때문이다.

결국 $\mathrm{MDGs}$ 의 효과적인 달성을 위해서는 취약국가의 빈곤감소와 사회발전의 과제를 풀어야 하며 이를 위해서 이들 국가의 취약성을 극복하기 위한 보다 직접적인 정책적 노력이 필요하다는 것이다.

\section{2. 세계적 평화와 취약국가}

취약국가의 개념이 국제적으로 관심을 모으게 된 또 하나의 계기는 세계적으로 발생하는 테러, 조 직적 범죄, 불법이민과 인신 매매 등 국제적 안전과 세계평화를 위협하는 요소로서 취약국가가 지 목되면서이다. 2001년 미국에서 발생한 9.11 테러는 이러한 시각이 가장 극명하게 대두되게 된 사 건이라 할 수 있다. 이 밖에도 2005년 런던 지하철테러사건 등 국제적인 테러의 많은 경우가, 취 약국가의 공권력의 공백상태를 이용한 범죄 집단의 조직 강화와 테러 훈련에서 비롯된 것으로 알 려졌다.

취약국가가 테러리즘의 온상이 되면서 이들 국가를 어떻게 포위하고 다룰 것인가 하는 문제는 국제 안보문제 차원에서 비핵확산문제, 군비통제문제, 테러리즘 근절문제 등과 결부되어 취급되었으며 내 적으로는 군사적 개입 문제와 인도주의적 문제 등도 복잡하게 연계되어 있다(이조원 2008). 9.11 사건을 계기로 기존의 국제경제론에서 주로 광범위하게 사용되던 최빈개도국(Least Development Countries)의 개념이 국제정치론 쪽으로 이동하였고, 지난 5 년간 취약국가를 대상으로 하는 원조 방법은 국제개발 공동체의 우선순위가 되었다. 이러한 배경에서 취약국가론은 21 세기의 새로운 국 제질서와 안보의 환경을 아우르는 핵심적인 주제로 부각되었다

취약국가의 정치·사회적 불안정, 인권침해, 폭력 분쟁 등의 문제가 주변국에 전이될 가능성이 높 아지면서 개발협력에 대한 인식도 변화하였다. 개발협력이 기존의 개발도상국, 저개발국가에 국한 된 문제가 아닌 선진국 시민들의 안전을 보장하기 위한 정책으로 그 의미가 확대된 것이다.

또한 국제사회는 취약국가를 국제 공동의 해결과제로 인식하고 정책적 시급성도 한층 강화하였다. 주로 각국의 양자간 협력기구 등을 중심으로 시행되던 개발협력이 외교부, 국방부 등의 국가안전 을 다루는 부처까지 취약국가의 문제를 중요하게 다루고 있다.

Collier \& Hoeffler(2004)는 낮은 소득수준을 지닌 취약국에서 내란이 발생할 경우 평균 약 $\$ 540$ 억이 소요된다고 추정한다(이는 국제효과를 제외한 직접비용과 간접비용을 포함한 금액이다). 이 처럼 갈등을 예방하는 것이 훨씬 비용 효과적이라는 점에서 취약국가에 대한 적절한 전략과 지원 
의 필요성이 제기되고 있다. 효과적인 원조와 개발 비용의 증가를 차단하기 위해 공여국들은 취약 국의 정치, 경제, 사회, 안보 등의 상황에 따라 지원 비율과 집중도를 달리하는 양태를 보이고 있 으며 기존의 전통적 원조방식을 넘어 안보와 개발을 연계한 새로운 원조방식을 모색하기 시작했다.

\section{3. 개발협력의 폐해방지 (Do-No-Harm)}

1994년 르완다에서 발생한 대량학살은 분쟁방지와 평화구축이 얼마나 중요한 과제인가를 잘 보여 주는 비극적 사건이다. 이후에도 사하라 이남 아프리카 국가 등에서 인류의 보편적 가치에 반하는 범죄가 인종분쟁, 내전 등의 과정에서 발생했다. 이러한 과정에서 해당 국가의 역사적, 사회적 맥 락을 무시한 채 개발협력 정책을 전개하면서 오히려 정치적, 사회적 문제를 더 심각하게 만들고 있다는 반성이 제기되었다. 이러한 시각은 'Do No Harm' 정책으로 요약되는 데, 공여국은 경제, 외교적 활동이 개도국의 분쟁을 야기하지 않도록 최선의 노력과 정책적 배려를 해야 한다는 맥락 이다(Mary B. Anderson 1999). 이를 기초로 개도국의 지속가능한 개발과 평화 정착을 위해 안전 구축 시스템을 마련하고, 구체적인 정책을 실행해야 한다고 보았다.

'Do No Harm' 시각에서 볼 때 더욱 중요한 것은 개발협력에서 야기되는 일차적 폐해보다는 취약 국가의 특성을 충분히 고려하지 못해 발생하는 이차적 피해이다. 수원국의 발전에 기여하기 위해 만든 개발협력 프로그램이 의도한 것과 달리 수원국 발전에 부정적인 영향을 미치지 않기 위해서 는 취약국가 협력 사업에 일정한 규칙과 가이드라인을 제시하고 취약국가의 특성에 대해 보다 객 관적이고 체계적으로 접근할 필요가 있다.

\section{III. 취약국가의 개념과 이론적 검토}

취약국가는 국가적 취약성으로 인해 빈곤과 저개발로 어려움을 겪고 있는 국가를 가리킨다. 그러 나 취약국가의 발생 원인과 선정 대상이 다양하며, 국제사회의 반응도 다르기 때문에 취약국의 정 의는 공여기관마다 상이하게 나타난다. 최근 국제사회는 '취약국가'를 특정한 국가 상태를 지칭하 는 용어로 사용하고 있다. 국제사회의 정책 행위자들은 그들의 관심과 목표에 따라 취약국가를 개 념화하고 그에 따라 정책의제를 설정하고 있는데, 이에 따라 취약성(fragility)의 의미가 다양하게 사용되고 있다. '실패한(failed or failing)', '위기의(crisis)', '약한(weak)', '악한(rogue)', '붕괴된 (collapsed)', '불완전한 성과(poorly performing)', '비효과적인(ineffective)' 등과 같은 유사 단어가 혼용되기도 하며, 취약성이라는 의미의 상관관계, 인과관계가 명확한 이해 없이 혼용되기도 한다. 
Cammack, D. et al(2006)은 취약국 정의가 다양하게 인식됨에도 불구하고 공여주체들의 정의는 대 체로 세 가지 유형으로 나타난다고 보았다. (1) 국가의 기능(functionality), (2) 산출(ouputs), (3) 공여자와의 관계(relationship)이다.

우선, 기능 면에서 취약국가란 국가가 시민들의 안보와 복지를 수행하는 능력 또는 의지가 부족한 경우를 가리킨다. 국가는 시민들의 권리와 생계를 보호할 수 없고 규제 권한이 없다. 국가와 시민 사이의 '사회 계약(social contract)'이라는 구분이 모호할 뿐 아니라 대중들은 의사결정에 참여할 권리가 거의 없으며, 국가는 이러한 긴장관계를 완화시킬 수 있는 수단이 약하다.

둘째, 산출 면에서 취약국가란 빈곤, 폭력, 테러, 난민, 전염성 질병 등의 악화 상태가 발생할 것 으로 예상되는 국가를 말한다. 국가는 사회질서를 확보하는 데 실패하였기 때문에 사회는 무질서 와 불법으로 혼란을 겪고 있다. 한편 분쟁 후 국가(post-conflict states)는 대량살상무기(WMD) 와 범죄 위협을 노출시키기 때문에 미국을 포함한 일부 공여국가들은 빈곤감소, 인권탄압에 비해 테러방지를 위한 목적에 더 많은 관심을 보이며 취약국가를 지원하기도 한다.

셋째, 국제관계 면에서 취약국가란 국가들과의 상호관계가 어려운 파트너(difficult partners)를 의미한다. 취약국가 분류 시 국가 그 자체의 특성보다 관계에 더 많은 영향을 받기도 한다.

결국 취약국가는 이를 사용하는 주체에 따라 다양한 정의를 갖는다. 예를 들어 위험(insecurity)을 우선적으로 생각하면 '국가실패(state failure)', '붕괴된 국가(collapsed states)'와 같은 단어를 사용 하는 경향이 있고, 개발(development)에 관심이 있는 경우 '어려운 파트너십(difficult partnerships)', '부족한 성과(poor performers)'를 언급할 것이다. 인도주의적 접근으로는 주로 '분쟁 후(poseconflict)'국가 재건 또는 '실패(failed)'국가라는 표현이 있다. 외교적인 이유에서 일부 공여국은 취약(fragile)이라는 용어가 결례로 인식될 수 있기 때문에 이러한 표현 대신에 원조 파트너십과 과정을 강조하기도 한다. 다음 절에서는 취약국가를 보다 자세히 이해하기 위해 주요 개발협력 기 관들의 취약국가의 개념, 원인, 특징, 중요성을 다뤼보기로 한다.

\section{OECD/DAC의 취약국가 개념}

$\mathrm{OECD}$ 는 취약국가를 국민들에게 기본적 공공서비스를 제공할 의지 또는 역량이 없는 국가로 정의 한다. 이러한 국가는 대부분 거버넌스가 취약하고 만성적인 빈곤에 노출되며 사회갈등, 폭력 및 내전이 심각한 사회문제를 야기한다(OECD 2007). 이러한 특징은 개발 비용을 증가시키는 등 원 조 효과성을 저해하기 때문에 공여국 및 수원국 정부의 정책집행을 방해하는 요소가 된다. 
이에 $\mathrm{OECD} / \mathrm{DAC}$ 은 2007년 '취약국가와 취약상황에 대한 국제개입의 원칙'을 발표하여 다음과 같 은 권고사항을 제시하였다. 첫째, 공여국은 정치, 안보, 개발 목표 간의 연계성을 인식하고, 분쟁 방지를 원조 목적의 우선순위에 두어야 한다. 둘째, 공여국은 테러방지 메커니즘을 도입하여 수원 국의 장기적인 구조적 안정을 도모하고 다른 국제 원조기관 및 원조 행위자들과 조화를 통한 원조 활동을 해야 한다. 특히 취약국가에 대한 원조는 수원국의 우선순위를 고려하여 일관성 있고 신속 하며 장기적으로 제공되어야 한다. 셋째, $\mathrm{OECD} / \mathrm{DAC}$ 은 분쟁상황을 분쟁 발생 전, 분쟁 중, 과도 기, 분쟁 후 상황 등으로 구분하여 각 상황에 따라 공여국이 각기 다른 접근방식을 도입하여 수원 국의 평화유지를 도모할 것을 권고한다(OECD 2007).

특히 취약국가의 원조가 효과성을 발휘하기 위해서는 해당 지역 내의 평화건설과 동시에 이루어져 야 한다고 보고 개발과 안보의 연계를 강조한다. 구체적으로 취약국가의 안보시스템개혁 (Security System Reform)에 대한 지원을 강조하였다. 이와 더불어 공여국과 수원국의 조화와 더불어 수원 국의 리더십과 주인의식의 향상, 역량개발에 대한 지원이 지속적으로 필요하다고 권고하고 있다.

\section{USAID}

$\mathrm{USAID}$ 는 취약국가가 개발과 인도주의 접근뿐 아니라 안보 측면에서도 중요한 의미를 갖는다고 보았다. 취약국가에 대한 이들의 지원은 냉전시대가 끝난 이후부터 2003년까지 줄곧 증가해왔다 (이라크 제외). 미국이 취약국가를 지원하는 이유는 크게 세 가지이다. 첫째, 2001년 일어난 9.11 테러는 정부실패의 영향이 국제적이라는 것을 증명한 사건이었다. 이를 계기로 미국은 개발의 역 할을 재평가하였고, 외교정책에서 국가안보를 핵심으로 인식하였다. 둘째, 취약국가에 대한 관심 이 상대적으로 부족하여 개발을 위한 추진력을 모으는데 실패해왔다. 이에 취약국가 분야는 인적 재해를 겪고 있으나, 성공적인 $\mathrm{MDGs}$ 를 달성하기 위해서는 취약국가의 지원이 필요하다. 셋째, 효 과적인 원조를 지향하는 21 세기 국제원조의 방향을 고려할 때 취약국의 원조 효과성을 최대화할 필요가 있다.

이러한 배경에서 USAID(2005)는 취약국가를 실패한 국가(failing and failed states)에서 회복 중 인 국가(recovering states)까지 넓은 범위로 규정한다. 그러나 범위 사이의 구별은 실제로 명확 하지 않으며, 이러한 표현은 실제 국가 내의 중요한 갈등 요소(폭동상태, 파벌 등)를 드러나지 않 게 할지도 모른다. 따라서 국가의 실패여부를 분류하는 것보다 국가가 안정권으로 들어서기 위해 얼마나 걸리는지 이해하는 것이 더 중요하다고 보았다. 이에 취약국가를 구별하는 방법으로 이미 위기(in crisis)에 있는 국가와 취약성(vulnerable)을 지닌 국가로 구별하는 방법을 제시하였다. 즉, 취약국을 취약성(vulnerability)과 위기(crisis)라는 두 가지 범주로 나누어 본 것이다. 
취약성(vulnerable) 측면에서 취약국가란 국민 대다수에게 안전과 기본적 서비스를 보장하려는 능 력이나 의지가 없는 경우를 의미하여, 정부의 합법성이 의문시 된다. 이는 실패하거나 위기로부터 회복 중에 있는 국가를 포함한다. 위기(in crisis) 측면에서 취약국가란 중앙정부가 그들의 영토를 효과적으로 통제하기 위해 노력하지 않으며 중요한 서비스를 보장하기 위한 능력이나 의지가 없는 경우를 의미한다. 정부의 합법성이 약하거나 사실상 존재하지 않고, 폭력적인 갈등이 실제로 나타 나 많은 위험에 노출되어 있다.

한편 Goldstone et al(2005)의 연구에서는 취약국을 분석하기 위해 효과성(effectiveness)과 합법성 (legitimacy)을 사용한다. 효과성이란 공익과 공공서비스를 제공할 수 있는 정부의 능력(capability) 을 의미한다. 합법성은 정부가 공정한 방법으로 힘을 사용할 때 보장된다. 효과성과 합법성은 안 보, 정치, 경제, 사회영역에서 거버넌스의 인식에 중요한 영향을 받는다. 이들의 관계를 다음의 표로 정리해볼 수 있다.

〈표 1〉 취약국의 거버넌스 분석: 취약 구조

\begin{tabular}{|c|c|c|}
\hline $\bar{\gamma}$ & 효과성(effectiveness) & 합법성(legitimacy) \\
\hline $\begin{array}{c}\text { 안보 } \\
\text { (security) }\end{array}$ & 군과 경찰은 국경을 보호하고 범죄를 제한함 & $\begin{array}{l}\text { 군과 경찰은 합리적으로, 공평하게 인권의 } \\
\text { 침해 없이 작동함 }\end{array}$ \\
\hline $\begin{array}{c}\text { 정치 } \\
\text { (political) }\end{array}$ & $\begin{array}{l}\text { 정치제도와 과정은 적절하게 시민의 필요에 } \\
\text { 대응함 }\end{array}$ & $\begin{array}{l}\text { 정치과정과 규범, 리더들은 시민들이 용인할 } \\
\text { 만함 }\end{array}$ \\
\hline $\begin{array}{c}\text { 경제 } \\
\text { (economic) }\end{array}$ & $\begin{array}{l}\text { 경제와 재정기관, 기본시설들은 경제성장을 } \\
\text { 지원하며 경제변화에 대응하고 천연자원을 } \\
\text { 관리함 }\end{array}$ & $\begin{array}{l}\text { 경제기관, 재정서비스는 천연자원에 투명하 } \\
\text { 게 접근함 }\end{array}$ \\
\hline $\begin{array}{c}\text { 사회 } \\
\text { (social) }\end{array}$ & $\begin{array}{l}\text { 취약하고 비주류들을 포함하여 기본적인 서 } \\
\text { 비스가 수요에 부응함 }\end{array}$ & 다양한 관습과 문화, \\
\hline
\end{tabular}

자료 : Goldstone et al(2005).

\section{DFID}

$\mathrm{DFID}(2005)$ 는 정부가 가난한 사람들을 포함한 대다수의 사람들에게 핵심기능을 할 수 없거나 하 지 않는 경우, 이를 취약국가로 정의한다. 빈곤 감소(poverty reduction)를 위한 정부의 핵심 기 능은 영토지배, 안보, 공적자원의 관리, 기본적 서비스 제공, 가난한 사람들을 지원하고 보호하는 능력이라 할 수 있다. 이처럼 $\mathrm{DFID}$ 는 단지 갈등을 겪는 국가만을 취약국가로 제한하지 않고 정부 가 주요한 기능을 하려는 의지(willingness), 또는 능력(capacity)이 있는가 여부에 따라 분류하고 있다. 아래의 표에서 보는 바와 같이 의지와 능력이라는 정부 기능의 구성요소 가운데 어느 하나 라도 부족할 경우 이를 취약국가로 간주한다. 
〈표 2〉 취약국을 나타내는 특징

\begin{tabular}{|c|c|c|}
\hline & 의지(willingness) & 능력(capacity) \\
\hline $\begin{array}{l}\text { 안보에 대한 } \\
\text { 국가의 권위 }\end{array}$ & $\begin{array}{l}\text { - 조직적으로 폭력에 영향을 받기 쉬운 } \\
\text { 집단에게 국가가 안보를 제공하지 않는 } \\
\text { 경우 }\end{array}$ & $\begin{array}{l}\text { - 국가의 국제적인 권위와 위상이 명확하지 } \\
\text { 못할 경우 } \\
\text { - 국가가 국경을 통제할 수 없는 경우 }\end{array}$ \\
\hline $\begin{array}{l}\text { 효과적인 } \\
\text { 정치력 }\end{array}$ & $\begin{array}{l}\text { - 대다수의 집단이 조직적으로 정치 } \\
\text { 과정에서 제외되는 경우 }\end{array}$ & $\begin{array}{l}\text { - 행정이 공식적, 비공식적 채널을 통해 } \\
\text { 통제되지 않는 경우 } \\
\text { - 정치참여에 효과적인 채널이 없는 경우 }\end{array}$ \\
\hline 경제 & $\begin{array}{l}\text { - 천연자원 추출의 공공관리에서 투명성이 } \\
\text { 없는 경우 }\end{array}$ & - 공공재정의 관리 수단이 부족한 경우 \\
\hline $\begin{array}{l}\text { 행정적 } \\
\text { 능력 }\end{array}$ & - 공공서비스를 특정 지역에 제한한 경우 & $\begin{array}{l}\text { - 국가가 세금을 GDP의 } 15 \% \text { 보다 덜 징수한 } \\
\text { 경우 }\end{array}$ \\
\hline
\end{tabular}

자료 : DFID(2005)

Brinkerhoff(2007)는 DFID의 취약국 선정 기준을 다음의 표로 재구성하였는데 대부분의 개발도 상국이 네 개의 범주에 포함된다. 'good performers'는 국가가 발전을 지속시키기 위한 능력과 정 치적 의지를 가지고 있을 경우, 국제사회 파트너십을 갖춘 국가에 해당한다. 'weak but willing'는 제한된 능력을 가진 국가를 의미하며, 'strong but unresponsive'란 억압적인 국가를 뜻한다. 마 지막으로 'at risk or failed'는 정치적 의지와 제도적 능력이 부족한 국가로서 개발(development) 이라는 부담에 노출되어 있는 국가를 말한다.

〈표 3〉Brinkerhoff의 DFID의 분류

\begin{tabular}{|c|c|c|c|}
\hline & \multicolumn{3}{|c|}{ 의지(willingness) } \\
\hline \multirow{2}{*}{$\begin{array}{c}\text { 역량 } \\
\text { (capacity) }\end{array}$} & weak & weak & strong \\
\cline { 2 - 4 } & strong & at risk or failed & weak but willing \\
\cline { 2 - 4 } & & strong but unresponsive & good performers \\
\hline
\end{tabular}

자료 : Brinkerhoff(2007).

그러나 지속적인 국제원조에도 불구하고 취약국가의 상황이 호전되지 않음에 따라 원조 피로(aid fatigue)라는 표현이 등장하였다. $\mathrm{DFID}(2005)$ 설명에 따르면 그 원인은 원조의 양이 충분하지 않 으며, 위기가 발생하기 전에는 충분한 지원을 하지 않고, 단기적이고 비협조적인 사업 수행으로 효율성이 낮기 때문이다. 대개 공여국은 취약국에 위기가 오기 전까지는 지속가능한 원조를 제공 하지 않으며, 정부성과에 기초하여 원조여부를 결정하기 때문에 갈등이 발생한 국가에는 역설적으 로 원조의 양을 줄이는 경향이 있다. 따라서 공여국과 수여국의 관계, 공여국의 원조 패턴과 원조 환경의 이해를 바탕으로 세밀한 정책 개선(policy reform)이 요구된다. 


\section{4. 취약성의 세 가지 측면}

OECD, USAID, World Bank, 그리고 CIDA (Canadian International Development Agency) 등 은 다양한 측면의 객관적 지표와 자료를 사용하여 취약국가를 선정하고 평가한다. 취약국가 선정 기준은 각 모형에 따라 다소 차이가 있으나 전반적으로 취약국으로 선정된 대상국은 거의 일치하 고 있다. 이들 기구들은 거시적인 차원의 범주를 구분한 뒤 각 범주에 적절한 지표들을 설정하여 데이터를 분석, 최종적인 취약성 지수를 산출하는 모형을 채택하고 있다.

여기서 좀 더 종합적 측면에서 취약국가를 접근하는 $\mathrm{CIDA}$ 의 $\mathrm{ALC}$ 모형을 살펴볼 필요가 있다. $\mathrm{ALC}$ 는 권위(authority), 정당성(legitimacy) 그리고 능력(capacity)을 의미하는 것으로 이러한 세 가지 측면에서 각각의 취약성 점수를 산출한 후 개별 국가의 취약성을 좀 더 심층적으로 분석하고 있다(CIFP 2006). 국가의 취약성은 다양한 원인에 의해 발생하는데, 취약국가들마다 서로 다른 취약성의 원인을 갖고 있으며, 이에 따라 그들이 갖고 있는 취약성도 서로 다르게 나타나게 된다. 따라서 각각의 취약국가에 적절한 빈곤감소 및 지속가능한 개발 정책을 추진하기 위해서는 각각의 취약국가들의 취약성 구성과 특징을 파악하는 것은 매우 중요하다. 이러한 면에서 CIDA가 제시하 는 ALC 모델은 취약성을 그 하위 구성요소로 세분하여 분석할 수 있게 하며 국가별로 취약성이 어떻게 구성되어 있는지 파악하게 해준다고 보인다.

그러나 CIDA가 제시하는 권위(authority)와 정당성(legitimacy)은 둘 다 정치적 측면을 다루는 지 표라고 볼 수 있다. 중요한 차이는 국가가 정책을 집행하면서 국민에게 행사하는 권위(authority) 와 그 과정에서 국민이 국가에게 부여하는 정당성(legitimacy)이라는 측면에서 보면 권위와 정당 성은 정치적 신뢰의 방향성이라는 측면에서 차이가 있다. 따라서 권위와 정당성은 취약국가의 정 치적 측면을 서로 다른 각도에서 바라볼 수 있게 한다. 한편 능력(capacity)은 행정, 정책적 측면 에서 국가가 국민에게 공적 서비스와 복지를 제공할 수 있는 능력을 갖고 있는가를 다룬다. 그러 나 취약국가에서 중요하게 제기되는 또 다른 이슈로 국가 혹은 통치자의 국민들에 대한 이러한 서 비스의 제공 의지(willingness)의 존재 여부가 있다. 능력(capacity)과 의지(willingness)라는 지표 를 국가의 행정(governance)측면으로 함께 묶어서 볼 수 있을 것이다.

취약국가의 특성을 규정하는 세 번째 측면은 안전(security)이다. 여기서도 두 가지 지표를 생각할 수 있는데, 첫 번째로 다른 국가 혹은 그 밖의 군사적 세력에 의해 국가의 안전을 위협받는 외부 적 위기(external crisis) 상황으로 국가의 취약성이 발생할 수 있다. 이와 대조적으로 국가 내의 갈등과 반목이 내부의 소요나 불안정을 야기할 수 있으며, 이것이 확대되어 내전으로도 연결될 수 있는데 이로 인한 취약성은 내적 폭력(internal violence)에 의한 것이라고 본다. 
아래 그림은 지금까지 논의를 통해 $\mathrm{CIDA}$ 의 $\mathrm{ALC}$ 모형을 비판적으로 수정한 것이다. 취약성을 정 치적, 행정적, 안보적 측면에서 나누어 보고 이들 세 가지 측면을 각각 구성하는 두 가지 지표를 제시하고 있다. 이를 통해 취약국가들의 취약성의 구성에 있어서의 독특성을 살펴볼 수 있을 것으 로 판단된다. 이러한 취약성 구조의 파악은 공여국 측면에서 개발협력 정책을 수립하고, 정책을 집행해 나가는데도 매우 유용한 틀을 제공할 것이다. 각각의 공여국마다 역량이 다르기 때문에 공 여국에 맞는 취약성에 초점을 맞출 수 있도록 하는데 활용될 수 있을 것이기 때문이다.

\section{〈그림〉 취약국가의 세 가지 측면}

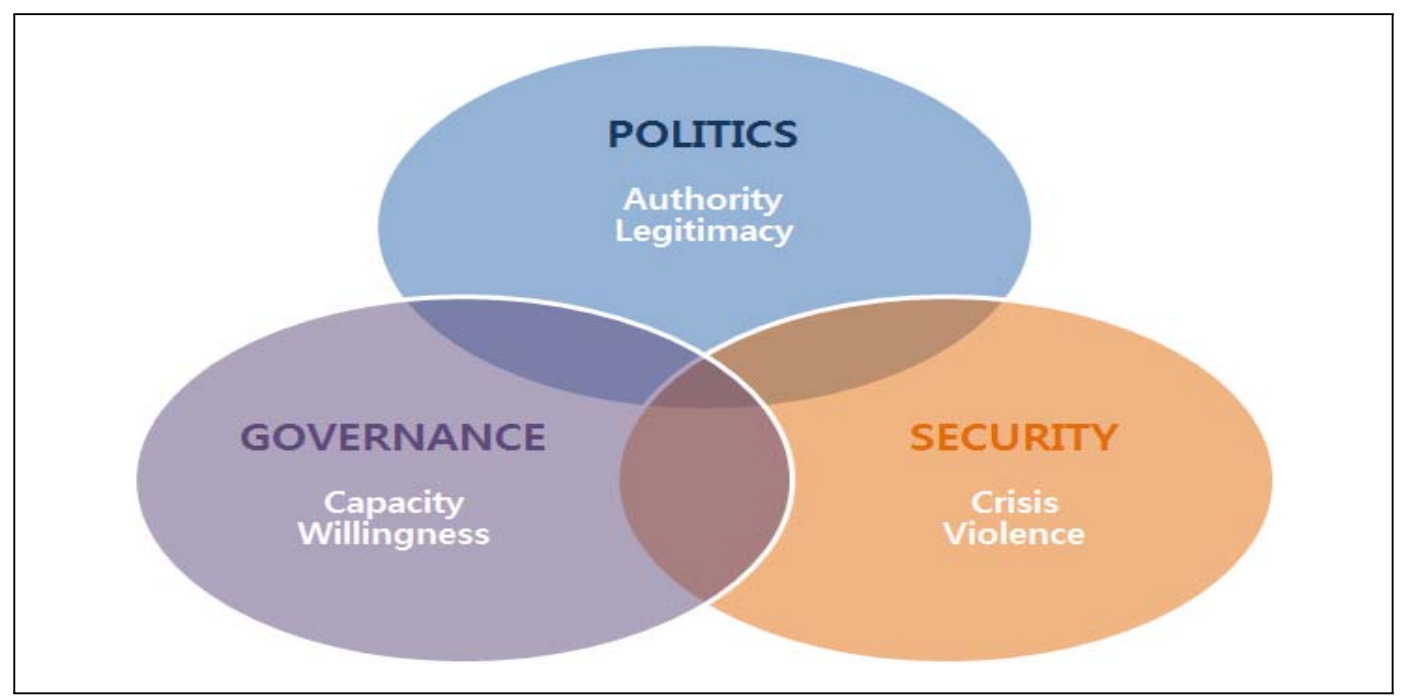

\section{IV. 분쟁 및 취약성에 관한 국제네트워크 : OECD/DAC의 INCAF}

취약국가의 개념을 기초로 개발협력 정책을 수립·집행함에 있어서 각각의 공여국이 서로 다른 입 장에 기초하여 원조사업을 하게 되면 원조의 효과성은 높을 수 없을 것이다. 취약국가에 대한 공 적원조의 조화를 위해 $\mathrm{OECD} / \mathrm{DAC}$ 은 INCAF(Internatinal Network of Conflict and Fragility)라 는 네트워크를 구성하게 되었으며, INCAF는 취약국가원조에 있어서 통합적 접근방법을 기반으로, 원조 공여국가들 간의 국제적 협력을 촉진시키고 취약국가 지원을 위한 가이드라인을 제시해주는 역할을 하고 있다. 따라서 개별 국가들은 $\mathrm{INCAF}$ 의 원칙 및 가이드라인을 바탕으로 구체적인 지원 원칙 및 전략들을 마련하고 있다. 이 절에서는 INCAF의 배경 및 여기서 제시하고 있는 취약국가 에 대한 개발협력정책의 가이드라인에 대해 살펴보기로 한다. 


\section{INCAF $^{2}$ 의 형성경로}

$\mathrm{INCAF}$ 는 세계에서 가장 도전적인 개발 환경에서 효과적이고 합법적인 국가 제도뿐만 아니라 평 화구축을 지원하기 위하여 정부와 국제기구들이 함께 모인 네트워크이자 독특한 의사결정 포럼이 다. INCAF는 최신의 정책과 프로그램들을 마련하고 공여국과 파트너 국가들 사이에 대화 촉진자 로서의 역할을 함으로써 공여국, 국제기구, 그리고 파트너 국가들이 분쟁과 취약성에 대응하여 빈 곤감소 등 개발협력의 효과성을 향상시키는 것을 목표로 하고 있다.

INCAF의 설립배경으로는 취약성과 폭력적인 분쟁을 가진 국가들의 MDGs 달성 성과가 느리게 진 행되는 데 대한 국제 공동체들의 우려가 높아졌다는 데 있다. 취약국가의 가난한 사람들은 안전을 보장하고, 분쟁을 방지하고, 인권을 보호하고, 개발을 위한 기본적인 기능을 제공하기 위한 의지 나 역량이 부족한 국가에서 살고 있다. 이러한 취약국가의 문제는 거기서 그치는 것이 아니라 주 변지역으로 이전되는 효과(spillover effects)3)를 갖고 있으며, 이 점에 대해서는 원조·개발 기구 뿐만 아니라 많은 $\mathrm{OECD}$ 정부들도 관심을 가지고 있다.

1990년대 초반부터 DAC는 분쟁, 평화, 개발협력의 관계를 분석하고 이에 대해 효과적으로 대응하 기 위해 네트워크를 형성하여 대응하였다. 그 중 첫 번째가 분쟁, 평화와 개발협력을 위한 네트워 크(CPDC: Network on Conflict, Peace and Development Cooperation)이다. 2005년에는 보다 직접적으로 가장 도전적인 개발 환경이라고 할 수 있는 취약국가를 다루기 위해 $\mathrm{DAC}$ 의 취약국가 그룹(FSG: Fragile State Group)을 출범시켰다. FSG는 다양한 논의를 통해 취약국가에 대한 개 발협력에 필요한 정책 가이드를 개발하여 왔다(OECD/DAC 2006).

이렇게 진행된 취약 국가들에 대한 국제협력은 2008년 12월 초에 이르러 취약 상황에 대한 DAC 의 참여에 있어서 한 단계 중요한 변화를 가져오게 되었다. 이는 $\mathrm{CPDC}$ 와 $\mathrm{FSG}$ 를 하나의 포럼으로 합하여, 새로운 분쟁과 취약성에 대한 국제 네트워크(INCAF)를 구성하게 된 것이다. INCAF는 원 조 효과성에 대한 조사 위원회(Working Party)에 대하여 상호 보완적인 기능을 수행하기위하여 설치되었다. INCAF 활동의 초점은 취약·분쟁 국가에 있지만 안보, 평화 구축, 국가 역량에 대한 실질적인 정책 이슈들을 검토하는 것과 관련된 원조 관리에까지 범위를 확장하고 있다. INCAF는, Accra 정신에 따라, 파트너 국가들과 함께 일을 함으로써 포괄적인 접근방법을 취하고 있다.

2) www.oecd.org/dac/incaf에서 소개하고 있는 INCAF의 주요 내용들과 관련된 PDF자료들을 바탕으로 종합하여 서술하 였음.

3) 사람, 마약, 범죄와 테러의 매매와 수출 


\section{INCAF 구성 및 주요 기능}

$\mathrm{INCAF}$ 는 $\mathrm{OECD} \mathrm{DAC}$ 의 부속기구로, 정부와 국제기구들로부터 모인 평화, 안전, 거버넌스 그리고 개발 효과성 이슈들에 관한 전문가들로 구성되어 있다. 이 네트워크는 UN, NATO, World Bank 등 분쟁과 취약성을 다루는 쌍무적-다국적 기관들과 밀접한 파트너십을 가지고 일하고 있다. $\mathrm{INCAF}$ 는 또한 회담과 정기적인 대화를 통하여 남-남 협력 제공자들을 연결시킨다. INCAF는 보 다 효과적인 정책의 일관성(coherence), 조화(coordination), 상보성(complementarity)(3C)을 확 보하기 위하여 일을 하는 데 있어서 'whole-of-government/system' 접근방법을 추구하고 있다.

$\mathrm{INCAF}$ 의 3 가지 주요 기능은 다음과 같다.

- 본부와 파트너 국가들4)의 현장 수준에서의 모범적인 실천과 이를 통해 배운 교훈들을 고취(홍 보)시킨다.

- 국제적인 규범을 설정하고 세계적으로 또 현장에서의 결과들을 점검한다.

- 분쟁과 취약성에 대한 원조국가의 대응을 향상시키기 위하여 실질적인 가이드를 제공한다.

INCAF는 'whole-of-government'적 접근에 기반하여, 전통적인 원조 관리를 넘어서 안전과 분쟁 방지, 평화구축과 정부건설과 같은 중요한 정책 이슈들을 검토한다.

Whole of Government Approach란 “목적을 달성하기 위해 수행되는 정부 기관들의 활동의 효과 성을 높일 수 있도록 이들의 활동범위에 대한 설계와 집행을 조정하기 위하여, 수원국가 내에 있 는 서로 다른 기관들을 가로지르는 공식/비공식적 네트워크들을 적극적으로 사용하는 것”으로 정 의되어진다(OECD 2010a).

취약 국가의 특수한 요구에 대응하기 위해서는, 인도주의적 지원, 외교, 안보, 사법, 부채탕감과 같은 재정적 도구를 포함하는, 원조에 대한 추가적인 도구의 사용이 종종 요구된다. 따라서 Whole of Government Approach는 개발 원조와 인도주의적 지원에 책임이 있는 기관들뿐만 아니라, 정 치, 안보, 사법, 재정적 문제 등에 책임을 가지고 있는 기관들을 포함한 국제적 행위자들의 일관 된 대응을 요구하는 것이다.

취약 국가에 대한 Whole of Government Approach를 뒷받침하는 데 중요한 것은 장기간 안정 성, 정부건설을 위한 지원, 그리고 개발은 그러한 접근에 거버넌스와 제도적 역량 구축이 함께 진

4) 파트너 국가란 다른 국가들로부터 자신들의 발전을 위한 개발 지원을 제공받는 국가를 말함. 
행되어졌을 때에만 달성되어질 것이라는 인식이다. 이러한 접근들은 반드시 적시에(기다려서는 안 됨. 예를 들어, 분쟁이 끝날 때까지 기다림) 그리고 유연하게(발생한 환경에 적응하는 것) 이루어 져야 한다(www.oecd.org/dac/fragilestates/wga).

\section{3. 취약국가 개발협력의 가이드 라인}

$\mathrm{CPD}, \mathrm{FSG}$ 와 INCAF로 연결되는 $\mathrm{OECD} / \mathrm{DAC}$ 의 취약국가 네트워크는 다양한 연구와 회원국의 전 문가들 사이의 논의를 바탕으로 취약국가에 대한 개발협력에 있어서 $\mathrm{ODA}$ 기구들이 따라야 할 몇 가지 가이드라인을 제시하여 왔다.

이중 가장 먼저 나온 것은 'Conflict, Peace and Development Co-operation on the Threshold of the 21 Century(1997)'라는 DAC의 정책 보고서이다. 이 보고서에서 제시하고 있는 가이드라인 은 취약국가가 분쟁상황을 겪고 있는 경우 그 단계를 고려한 접근이 필요하다는 것을 강조한다.

\section{분쟁단계에 따른 취약국가 지원 가이드라인(1997)}

\section{분쟁 발전 이전 단계}

- 개발협력을 통해 수원국의 민주적 사회 안정 촉진을 지원할 것

- 수원국의 구조적 안정을 지속적인 개발의 기반으로 인식하고 평화구축 및 분쟁 방지를 목표로 할 것

- 수원국 내 분쟁방지와 안정을 도모하기 위해 경제성장, 빈곤감소, 민주화, 건전한 거버넌스 및 인 권존중을 위해 노력할 것

\section{분쟁 진행 단계}

- 분쟁 초기단계에는 분쟁원인 분석-파악해 수원국의 평화구축 및 분쟁방지를 지원할 것

- 분쟁 중에는 인도주의적 지원, 외교적 조치 및 정치경제적 조치 등을 중심으로 분쟁 후 국가의 재건을 위한 장기적 지원 실시할 것

- 분쟁 국가에 대한 주변 지역의 지원에 노력할 것

\section{분쟁 종결 단계}

- 평화가 정착되지 않은 취약한 상황에서도 지속 가능한 평화체제로의 전환을 지원해야 할 것

- 화해 모색 및 새로운 폭력적 갈등 사태의 방지를 위해 지원할 것 


\section{분쟁 종결 이후 단계}

- 인도적 지원, 국가재건 및 개발협력 간의 충돌이 없도록 지원할 것

- 정치·법·경제·행정적 개혁을 통해 합법적인 정부기관 및 제도 구축을 지원할 것

- 국제적으로 합의된 원칙에 따라 긴급구호 및 재건활동 이행할 것

- 수원국의 개방적이고 참여적인 대화를 지원할 것

- 평화 구축과 분쟁 방지 지원에 대한 모니터링과 평가 실시할 것

2001년 OECD/DAC은 분쟁을 미연에 방지하는 노력이 매우 중요하다는 차원에서 개발도상국가의 분쟁을 막도록 하는 가이드라인 'The DAC Guidelines Helping Prevent Violent Conflict(2001)' 를 제시하였다.

\section{분쟁방지를 위한 개발협력 가이드라인(2001)}

1. 분쟁상황에서의 공여국의 효과적인 개발협력을 위한 원칙 준수할 것

- 제한된 자원의 이용효과를 극대화 할 수 있는 분야에 우선 지원할 것

- 공여국의 개발활동은 수원국의 주인의식 강화, 평화구축 및 사회 안정을 우선 목표로 할 것

- 공여국과 수원국 간의 상호 신뢰 향상과 지속가능한 정책 개발을 위해 관련 기관 및 책임자와의 원활하고 투명한 소통을 지원할 것

- 다양한 행위자의 포괄적인 참여를 통한 대화를 장려할 것

- 공여국은 수원국의 자원을 활용하여 수원국의 역할을 강화할 것

- 여성문제를 폭력분쟁 방지 및 평화구축 관점에서 이해할 것

- 전쟁 피해 아동 및 청소년에 대한 정책적 지원을 실시할 것

- 복잡한 분쟁상황에서 신속하고 유연하게 대응하며 장기적으로 수원국의 사회 안정 및 복구에 기 여할 것

- 공여국간의 원조조화를 통해 수원국 내 분쟁 완화 및 평화 증진을 지원할 것

- 공여국간 통합되고 일관된 활동 및 정책을 수립할 것

- 지역협력 강화를 지원할 것

2. 분쟁방지를 위한 공여국간 통합된 협력 기준 도입할 것

- 수원국의 사회 안정을 위해 분쟁방지와 평화구축을 원조 지원의 목표로 설정할 것

- 분쟁과 위험 분석 및 평가를 통해 잠재적인 문제 요인과 대안을 파악하고 분쟁방지의 주류화를 통해 기타 정책과의 일관성을 높이도록 할 것 


\section{3. 안보문제와 개발의 연계를 통한 평화증진을 지원할 것}

- 안보체계의 개혁은 분쟁방지를 통해 경제개발의 효과성을 증대시킬 수 있으므로 건전한 거버넌스 의 구축의 일환으로 추진할 것

- 안보는 건전한 거버넌스와 평화, 지속가능한 개발을 보장하는 개발협력 이니셔티브의 필수요소임 을 인식할 것

\section{4. 수원국의 평화구축 절차를 지원할 것}

- 공여국은 분쟁의 완화, 억제, 해결 과정에서 원조와 연계된 목표를 명확히 할 것

- 시민사회, 종교집단, 전문가 협회, 여성그룹, 학회 등이 평화구축에 대해 건설적인 자문을 제공할 수 있는 기회를 제공할 것

- 수원국의 역량 강화와 평화구축을 위한 이니셔티브를 지원할 것

- 공여국은 평화구축에서의 여성의 중요성을 인식할 것

- 민주화를 통한 평화구축을 지원할 것

5. 공여국은 수원국의 파트너십 강화를 통해 평화 증진을 도모할 것

- 수원국 역량 및 건전한 거버넌스 개발을 지원하고 신뢰관계를 강화할 것

- 공여국은 수원국 내 시민사회와의 파트너십을 강화할 것

- 효과적인 파트너십 구축을 위해 공여국 간의 정책 일관성과 협력을 강화할 것

6. 비즈니스와 개발을 연계하여 평화증진을 지원할 것

- 공여국은 수원국내 사회 안정화와 무력분쟁 방지에 기여하는 민간주도의 경제성장을 지원할 것

1997 년도에 취약국가로 여겨진 35개 국가들은 2009년에도 여전히 취약국가로 분류되고 있으며 이 들과 다른 개발도상 국가들 사이의 갭은 1970년대 이후 점점 더 벌어져가고 있다. 보다 강력한 국 제적인 참여모형 없이는, 이 국가들은 계속 뒤떨어지게 될 것이다. 이러한 현실에 대응하기 위해 OECD 회원 국가들의 개발협력기구들은 'The DAC Principles for Good International Engagement in Fragile States and Situations(2007)'를 마련하여 개발협력 정책에 적용하도록 하였다. 


\section{취약 국가와 취약상황에 대한 국제사회의 모범적인 개입원칙 10가지(OECD 2007)}

- 먼저 전· 후 상황을 파악하라.

- 피해를 주는 활동이 없는지 확인하라.

- 핵심 목적으로써 국가 건설에 초점을 맞춰라.

- 우선순위에 얽매이지 말라.

- 정치, 안전 그리고 발전 목표들 사이의 연결고리를 인식하라.

- 포괄적이고 안정적인 사회를 위한 기초로써 비차별주의를 증진시켜라.

- 다양한 방법과 맥락으로 지역의 우선순위들을 조정하라.

- 국제적인 활동가들 사이에 실질적인 조정 메커니즘에 합의하라.

- 빨리 행동하라. 하지만 성공할 수 있는 기회를 가질 만큼 충분히 오랜 시간 머물러라.

- 배제되는 사람들이 없도록 방지하라(“원조 고아”).

2010년 4월 동티모르의 Dili에서 공여국 및 수원국 개발협력정책 결정자들이 취약국가 행동강령을 천명하였다. 이러한 Dili 선언(Dili Declaration: A New Vision for Peace Building and State Building)은 2010년 4월 8일 Dili에서 합의된 G7+성명에 기초 하고 있으며, 원조 효과성에 대한 파리선언, 취약 국가와 취약상황에 대한 국제사회의 모범적인 개입원칙, 실천행동을 위한 Accra 아젠다(AAA)에 대한 참여국들의 책무를 재차 확인하였다. Dili 국제 대화의 참여자들은 분쟁·취 약 국가들에 있어서 $\mathrm{MDGs}$ 달성을 위한 디딤돌로서 7 가지 평화구축과 정부건설 목표를 규정하였 다. Dili 선언의 목표는 2011년 열릴, 다음번 대화 회의를 위한 토대를 제공할 것이다.

\section{평화구축과 정부건설을 위한 목표(OECD 2010b)}

- 포괄적인 정치적 합의와 과정, 그리고 포괄적인 정치적 대화를 촉진한다.

- 기본적인 안전과 보안을 구축하고 강화한다.

- 평화적인 갈등해결과 정의에 대한 접근을 달성한다.

- 서비스 전달을 촉진시키기 위하여 효과적이고 책임 있는 정부 기관들을 개발한다.

- 지속가능한 생계, 고용 그리고 효과적인 천연자원의 관리를 포함한, 포괄적인 경제 발전을 위한 기반 을 마련한다.

- 화해와 평화적 공존을 위한 사회적 역량을 개발한다.

- 지역적 안정성과 협력을 조성한다.

지금까지 $\mathrm{OECD}$ 의 $\mathrm{INCAF}$ 등을 중심으로 취약국가에 대한 개발협력 가이드라인을 살펴보았다. 실 제로 이러한 가이드라인은 취약국가 개발협력에서 준수해야할 내용들임이 분명히 드러난다. 이러 
한 가이드라인은 내용의 독특성 보다는 공여국가 및 수원국가들이 취약국가들에 개발협력을 함에 있어서 공유하고 원조의 효과성 제고를 위해 공동의 노력을 할 수 있도록 하는 데 큰 의의가 있 다. 가이드라인에서 읽을 수 있는 다른 의미는 INCAF를 중심으로 점점 취약성 해결이 개발협력의 효과성에 가장 중요한 관건으로 인식되고 있다는 점이다. 분쟁의 단계별 접근에서 분쟁의 방지에 초점을 두던 가이드라인이 취약국가에 대한 개입의 원칙, 취약성을 극복하고 평화체제를 극복하는 것으로 초점을 옮겨가고 있다는 것이다.

\section{V. 한국의 취약국가 협력 정책에 대한 시사점}

앞에서 언급한 바와 같이 OECD/DAC은 2010년 4월 Dilli 행동계획에 대한 성과를 2011년 서울에 서 열리는 4차 개발협력 고위급 회담(High Level Forum 4)에서 검토하고 향후 방향을 논의하기 로 하였다. 이뿐만 아니라 이제 $\mathrm{OECD} / \mathrm{DAC}$ 의 회원국으로서 활동하고 있는 한국은 국제 개발협력 기구들과 조화와 협력을 이루어 취약국가에 대한 구체적인 정책을 수립하여 나가야 할 것이다. 이 과정에서 앞에서 제시한 가이드라인을 준수하는 것은 물론 취약국가에 대한 개발협력 정책에서 한 국이 기여할 수 있는 전략적 영역을 파악해야 할 것이다.

물론 그동안의 한국 $\mathrm{ODA}$ 를 보면 취약국가로 분류될 수 있는 국가들에 대한 개발협력을 적극적으 로 실시해 온 것이 사실이다. 예를 들어 동티모르, 라오스, 미얀마 등 동남아시아의 취약국가 등 을 비롯해 아프가니스탄, 예멘, 이라크 등 회교권의 취약국가에 대해서도 많은 노력을 경주해 왔 다. 이 밖에도 수단, 앙골라, 코트디부아르, 콩고 등 아프리카 국가 등에 대해서도 개발협력을 실 시해 왔다. 그러나 이러한 취약국가들을 지원하면서 취약성을 고려한 일관성 있는 정책을 실시해 왔다고 보기는 어려운 것이 사실이다. 한국의 $\mathrm{ODA}$ 효과성을 높이고, 국제 개발협력 기구들과 효 과적인 공조를 위해서는 한국의 취약국가에 대한 정책이 절실한 상황이라고 판단된다.

그러나 취약국가의 취약성은 단순히 해당국가의 내적 상황에 의해 규정되거나 해결되지 않는다는 점을 고려해야 할 것이다. 예를 들어 아프가니스탄, 이라크 등의 분쟁은 다분히 세계안보 및 국제 정치의 틀 속에서 이루어지기 때문에 한국이 이러한 국가들의 취약성 극복에 핵심적인 역할을 하 기 어려울 것이기 때문이다. 또한 수단이나 콩고 등의 국가에서 발생하는 분쟁과 이로 인한 취약 성은 역사적, 문화적 뿌리가 매우 깊어 쉽게 해결되기 어려운 과제이기도 한다. 그러나 앞에서 논 의한 바와 같이 취약성은 단순히 외부의 안보위협이나, 내부의 갈등에서만 비롯되는 것이 아니라 내적인 정치, 행정적 측면에서도 발생하기 때문에 한국이 독특한 역할을 할 수 있는 부분이 존재 
한다. 특히 취약국가의 취약성은 행정체제의 미비, 여성 및 아동 등의 취약계층에 대한 사회적 보 호 결여 등에서 발생하는 데, 이러한 영역에서 한국의 공적개발협력은 많은 긍정적인 결과를 창출 해왔기 때문에 한국이 의미 있는 기여를 할 수 있을 것으로 보인다. 뿐만 아니라 동티모르, 라오 스, 미얀마 등의 국가에서는 한국이 취약성을 극복하는데 핵심적인 기여를 할 수 있을 것으로 기 대된다. 이들 국가의 한국에 대한 신뢰와 미래의 상호관계에 대한 기대 등 제반 여건이 한국의 적 극적 노력과 결합할 때 효과성을 발휘할 수 있기 때문이다. 따라서 민주적 정치제도의 확립, 사회 의 질서 회복, 행정제도의 정비 등 취약성 극복을 위해 한국의 전략적 노력을 기대해 볼 만 하다. 이러한 과정에서 $\mathrm{OECD}$ 가이드라인을 준수하는 것은 반드시 필요하다.

한편 취약국가들 사이에 존재하는 $\mathrm{ODA}$ 불균등도 국제사회가 심각히 고려해야 할 것이다. 국제적 인 안보의 위협으로 인식되는 국가들에 대해서는 ODA 뿐만 아니라 국제사회가 다양한 방식으로 많은 노력을 투하한 반면, 르완다, 수단, 시에라리온 등의 분쟁은 많은 인명의 희생을 가져왔지만, 상대적으로 많은 정책적 관심의 대상이 되지 못했다. 취약국가의 정책을 모색하면서 원조의 사각 지대에 존재하는 취약국가에 대한 노력도 함께 하여야 할 것이다. 


\section{참고 문헌}

이조원(2008). 취약국가 모델과 북한에 대한 개발협력 연구. 「북한연구학회보」, $12(2)$ : 289-321.

BMZ-Federal Ministry for Economic Cooperation and Development (ed.)(2007).

Transforming Fragile States: Examples of Practical Experience. Baden-Baden: Nomos.

Brinkerhoff, Derick W. (a): 'Capacity Development in Fragile States: Dilemmas and directions'. Capacity.org Journal, Issue 32, December 2007. www.capacity.org/en/ journal/feature/dilemmas_and_directions. Accessed March 2009.

Cammack, D. et al(2006). 'Donors and the 'Fragile States' Agenda: A Survey of Current Thinking and Practice' ODI Report for the Japan International Cooperation Agency, Overseas Development Institute, London.

CIFP(2006), Failed and Fragile States 2006, A Briefing Note for the Canadian Government. November 2006.

DFID(2005). Why we need to work more effectively in fragile states. January 2005.

Goldstone, Jack A. et al.(2005). Strategy Framework for the Assessment and Treatment of Fragile States.

Mary B. Anderson(1999). Do No Harm: How Aid Can Support Peace Or War. Lynne Rienner.

OECD/DAC(1997). Conflict, Peace and Development Co-operation on the Threshold of the 21 Century. May 1997.

OECD(2001). The DAC Guidelines Helping Prevent Violent Conflict. OECD Publishing.

OECD/DAC(2006). Whole of Government Approaches to Fragile States. available at: http://www.oecd.org/dataoecd/15/24/37826256.pdf.

OECD(2007). Principles for Good International Engagement in Fragile States and Situations. available at www.oecd.org/dataoecd/61/45/38368714.pdf. 
OECD(2010a). Development Co-operation Report. available at: http://www.oecd.org /document/62/0,3343,en_2649_33721_42195902_1_1_1_1,00.html

OECD(2010b). Dili International Dialogue sets out a new vision for peacebuilding and statebuilding. available at: http://www.oecd.org/dataoecd/12/30/44927821. pdf

Paul Collier \& Anke Hoeffler(2004). The Challenges of Reducing the Global Incidence of Civil War. Center for the Study of African Economies, Department of Economic, Oxford University.

USAID(2005). Fragile States Strategy. January 2005. 